\title{
Research Paper: Socioeconomic Factors Affecting Adolescent and Youth Addiction to Synthetic Drugs
}

Mohsen Khosravi $^{1}$ (D), Bibiagdas Asghari ${ }^{1 *}$, Maryam Eskafi ${ }^{1}$ (D)

1. Department of Social Sciences, School of Humanities, Islamic Azad University, Gonabad Branch, Gonabad, Iran.

$\begin{aligned} & \text { Use yur device to scan } \\ & \text { and read the article online }\end{aligned}$
Drugs. Journal of Research \& Health. 2020; 10(2):123-132. http://dx.doi.org/10.32598/JRH.10.2.1546.1
dol http://dx.doi.org/10.32598/JRH.10.2.1546.1

\section{(c) (i) (3)}

Article info:

Received: 10 Nov 2019

Accepted: 25 Jan 2020

Publish: 01 Mar 2020

\section{Keywords:}

Addiction, Socioeconomic factors, Synthetic drugs, Youth, Adolescents

\section{ABSTRACT}

Background: The present study was conducted to investigate the social status of addicts in Birjand City, Iran. This research was carried out by using the survey method. The research population included all adolescents and young people who were addicted to narcotics since the beginning or have turned to synthetic drugs before the age of 30 .

Methods: The samples were selected using the available sampling method. A researcher-made questionnaire was used to study the social status of adolescents and youths of drug addicts. This questionnaire examines the family status as well as the individual characteristics of the samples.

Results: The results showed that most drug addicts belong to the social-ecological community of northern Birjand. Also, there is a significant relationship between the age of the person with the duration of addiction and the age of the onset of addiction, between education and the age of the onset of addiction, between the age of addiction and the frequency of use per day, and between the addicts in the family and the addiction to synthetic drugs.

Conclusion: The results showed that most drug addicts live in the social-ecological community of northern Birjand. Also, there is a significant relationship between the age of the person with the duration of addiction and the age of the onset of addiction, between education and the age of the onset of addiction, between the age of addiction and the frequency of use per day and between the addicts in the family and the addiction to synthetic drugs.

\footnotetext{
* Corresponding Author:

Bibiagdas Asghari, PhD.

Address: Department of Social Sciences, School of Humanities, Islamic Azad University, Gonabad Branch, Gonabad, Iran.

Phone: +98 (915) 1606542

E-mail: a asghari2002@yahoo.com
} 


\section{Introduction}

he third millennium started by many issues in different sectors, including the $\mathbf{T}$ problems of social change and its consequences in the psychosocial dimension of humankind [1]. One of the most critical social problems is drug addiction, and its increasing spread among the young generation as a global issue. Drug addiction is not just a personal behavior but a social behavior as well [2]. The problem of addiction and drugs is as ominous as the destruction of the environment, nuclear threat, or world famine crisis - one of the four major global disasters [3]. Drug abuse is a predictable process that usually begins with the recreational use of alcohol and cigarettes and continues with using marijuana (cannabis) and other narcotics, especially cocaine in urban environments [4].

According to the 2004 report of the United Nations Office on Drugs and Crime (UNODC), the number of drug abusers is estimated to be around 185 million that accounts for $3 \%$ of the world's population. Based on the statistics, marijuana is the most commonly consumed substance after cigarettes and alcohol in the world. Stimulants such as amphetamines, methamphetamine, and ecstasy are in the second row with a total of 30 million consumers. Opioid drugs include heroin, opium, and morphine with 15 million and cocaine with 13 million consumers stay in the third and fourth rows [5]. Studies show that most adolescents at the age of 12 or 13 start using drugs. Researchers believe that adolescents start using legal substances such as cigarettes and then turn to illegal drugs such as alcohol, psychotropic substances, and marijuana [6].

In almost all long-term studies, this chain begins with smoking, followed by alcohol, then grass, and finally, other drugs. Of course, the order of drug use in this chain is influenced by community attitudes, norms and the availability of drugs. Although drug use starts at younger ages, in no population, there is such a high rate of drug and cigarette smoking [7]. According to the statistics and reports of international organizations and institutions, attitudes and behavior patterns of people, especially young people, have changed along with the drug abuse pattern in all parts of the world, including Iran. This change is a transition from traditional drugs to synthetic drugs so that over the past 10 years, the rate of drug use has increased from $3 \%$ to $25 \%$ [8].

According to the census, young people are the largest age group in the population of Iran. The youthfulness of society is an opportunity as well as a treat, as the increase in the young population increases the vulnerability of the country to synthetic drug abuse [9]. Synthetic drugs are a broad category of drugs that are made in industrial laboratories with chemical processes. Synthetic drugs do not need special means for consumption, their volume is low and effects are strong, so many teenagers and young people use them. That is one of the reasons for changing their tendency from traditional drugs to synthetic drugs [9].

The age composition of the Iranian community can be both a great opportunity and a significant threat. Many consumers of synthetic drugs will suffer from mental illnesses, commit murder, high-risk sexual behaviors, suicide, and so on. These behaviors cause family breakdown and social anomalies. According to Tehran Counter Narcotics Police, crack, which is an indigenous drug, has spread among Iranian addicts and become the third drug in use after cannabis and opium, and more than $90 \%$ of consumers are young people under the age of 30 [10].

Many different studies investigated the various aspects of drug addiction, but none of them has been conducted in Birjand so far [11-16]. So this is one of the motivations of the researchers to carry out this research. Also, Birjand is the capital of the Southern Khorasan Province, which is located in the vicinity of Kerman, Sistan and Baluchestan provinces and has a $460-\mathrm{km}$ border with Afghanistan, the largest producer of drugs. Thus, Birjand is continuously exposed to the dangers of drug abuse. That is another reason to conduct this research in this city.

Besides, an exploratory interview was conducted by the researcher with the technical staff of the addiction retreat camp called Paradise Hidden. They stated that the rate of synthetic drug use had increased significantly. According to them, approximately $95 \%$ of people who recently admitted to the camp were synthetic drug addicts. The technical officer of Arad, a transitory center for reduction of harm, stated that the number of visits to this center has increased, and almost all referrers, including those with a case in this center and those who attended as a passer-by were synthetic drug consumers. The head of the anti-narcotics police in Birjand also said that the number of discoveries of industrial narcotics in 2016 was $90 \%$ higher than that in 2015 , and unfortunately, the younger ages (between 20-30 years) were the most frequent users.

The third volume of judicial cases in the country has been devoted to crimes about drugs according to the stra- 
tegic and social protection deputy of preventing crime [17]. Additionally, observations of the proficient narcotic experts indicated that $60 \%$ of this amount is related to synthetic drugs. This situation shows the importance of investigating this issue.

The tendency of young people to use synthetic drugs like other social phenomena does not have a single cause, and a combination of individual, social, economic, political, and cultural factors contributes to this tendency. These complex factors are continually changing at the individual and social levels. Personal reasons for young people to use synthetic drugs interact with family, society, school, and government factors [18]. But it seems that the social context of people has a more critical influence, among other factors, because it can cause other harmful effects. The social context is the social, economic, and cultural conditions in which one is born and develops, including the social origin of the individual, as well as the social, economic, and cultural characteristics of the family and the peer network.

A detailed search on the Internet shows a lot of research in this regard, which is a bit far from the issue and has emphasized mainly on the effective factors of the tendency to use drugs. For example, Jorablo [12] studied the factors influencing the change in the taste of consuming narcotics from traditional to synthetic drugs in Garmsar City, Iran. The research has five main hypotheses, all of which were approved. The research hypotheses were the relationships between structural, individual, social, and economic factors, as well as attitudes towards the tendency to use synthetic drugs. Raeesi Sartoshizi [11] in his MS dissertation on the social factors affecting the tendency of young people to use narcotic drugs (Case Study: Shahrekord City), showed a significant and negative relationship between variables of social class, social control, and the way to spend leisure times with the dependent variable (the rate of tendency to use drugs).

Also, the results of the research revealed a significant and positive relationship between the variables of the use of modern media, the unproductive family, and the association with inferior friends with the rate of the tendency to use drugs. But the findings did not show a significant relationship between the unemployment variable and the dependent variable. Ghadeghmat and Mahmoudi [19] investigated the factors of the tendency of young people to synthetic drugs in Dorud City. Statistical analysis showed that the primary influential factors in the propensity to addiction were the presence of addicted people in family and relatives, socializing with addicted friends, parents' divorce or their death, low educational level of the individual and his or her parents, lack of healthy recreation, ease of access to drugs, unemployment, and poverty.

The findings of Mirzaei Alaviyeh et al. [16] showed that the function of the family of the drug-dependent group in all areas, including general functioning, communication, emotional blend, role play, problem-solving, emotional attachment, and behavior control, was significantly more inappropriate than that of the normal groups. In the drug-addicted group, there were cases of loss of life components. The low educational level of research samples and their parents, low living standards, the presence of addicted father and brother, and the prevalence of drug abuse in friends were significantly higher than those in the non-addicted group.

The most frequently used synthetic drug in the addicted group was crystal. According to this research, the family function was different in two groups and family function was effective in the tendency of youth to industrial narcotics. Rasekh and Panahzadeh [20] investigated social factors affecting youth addiction (a case study of marginalized people in Shiraz City, Iran). The results of this study showed a significant relationship between variables of self-concept, education, access to drugs, family support, age, early sexual intercourse, self-esteem, and hope for the future, with drug abuse. Also, there is a relationship between the associated social variables, the place of residence, and the type of drug. Meanwhile, the researcher did not find any significant difference between the parents' education, parents' job, individual occupational status, ethnicity, addiction among household members, and drug abuse. Among the conducted studies, few studies have focused on the social context of drug addicts.

\section{Materials and Methods}

The method of this research was survey. The statistical population included all adolescents and young people who were addicted to narcotic drugs and synthetic drugs from the beginning, or have turned to synthetic drugs before the age of 35 years. According to the experts of Iran Drug Control Headquarters of South Khorasan Province, there are 19000 addicts in the province and 6115 in Birjand. Since the number of statistical population is unclear and the study topic is sensitive, the following formula 1 is used to determine the sample size.

$$
\text { 1. } n=\frac{\left(z_{1-\frac{a}{2}}\right)^{2} \times \sigma^{2}}{d^{2}}
$$


Table 1. Psychometric properties reliability

\begin{tabular}{cc} 
Variable & The Cronbach $\alpha$ \\
\hline Social context & 0.727 \\
\hline
\end{tabular}

The sample size was determined as 361 by Morgan Table. The samples were recruited using the convenience sampling method.

The following steps were taken to study the social and economic factors affecting adolescent and youth addiction to synthetic drugs:

1. Exploratory study; 2. Discovering the main concepts based on exploratory interviews; 3 . Examining the theories and concepts and designing the causal model; 4. Extracting hypotheses from the model and definition; and 5. observing and analyzing information.

A researcher-made questionnaire was used to study the socioeconomic factors affecting adolescent and youth addiction to synthetic drugs. This questionnaire examines the family situation of the interviewee in a $9 \times 9$ table. Also, 26 items of this questionnaire explored the conditions and personal characteristics of the interviewee. The researcher would complete the last two items.

In the content validity study, several professors were asked to submit their corrective comments in writing, after careful study of the questionnaire. It was also emphasized that in the qualitative assessment of the content validity, the following cases should be considered: considering the correct grammar, using proper words, the importance of questions being at their proper place, and the timing of the completion of the designed tool. After collecting the experts' opinions, necessary revisions were made to the questionnaire.

Table 2. Frequency distribution of the onset of drug use
The qualitative method was used in examining the face validity. Determining the qualitative face validity was conducted in a panel of 10 professional staff with the presence of experts to find difficulty level, the amount of disproportion, ambiguity of expressions, or the existence of inadequacy in the of the meaning of words. Their comments were applied in the questionnaire.

According to Table 1, the Cronbach $\alpha$ value for the social factor questionnaire is more than 0.7 , which evaluates the reliability of the questionnaire as desirable. In other words, it is possible to rely on the results obtained based on this sample and to ensure that the results remain stable if another sample replaces the statistical sample used.

\section{Results}

About $46.6 \%$ of the subjects were 24 to 30 years old. In terms of educational level, $63.1 \%$ of the subjects had not completed their education up to diploma. In terms of birthplace, $79.3 \%$ of respondents lived in Birjand City. Of these, $65.9 \%$ lived in the north part of the city. More than $18 \%$ lived in the center of the town. Others lived in Mehrshahr and the suburban areas.

The number of family members in $40.9 \%$ of the samples was 3 to 6 . About $48.4 \%$ of the samples were the second to the fifth child of their family. Also, $43.3 \%$ of them lived with their parents and $43.3 \%$ alone. About 58.2\% of the parents of sample members lived together. Besides, $70.4 \%$ of the samples have left school, and $50.6 \%$ of them did that because of "no interest in school." Most

\begin{tabular}{cccc}
\hline The Age of Drug Use Onset & No. & $\%$ & 20.5 \\
\hline Less than 9 years old & 67 & 19.2 & 33.8 \\
9 to 15 years old & 63 & 111 & 13.1 \\
16 to 22 years old & 43 & 13.4 \\
\hline Older than 22 & 44 & & \\
\hline
\end{tabular}


Table 3. Frequency distribution of family members' job

\begin{tabular}{ccccccccccc}
\hline Relationship & $\begin{array}{c}\text { High-Skilled } \\
\text { Employee }\end{array}$ & $\%$ & $\begin{array}{c}\text { Simple } \\
\text { Employee }\end{array}$ & $\%$ & $\begin{array}{c}\text { Self-Em- } \\
\text { ployed }\end{array}$ & $\%$ & Worker & $\%$ & No Answer & $\%$ \\
\hline Father & 6 & 1.8 & 3 & 0.9 & 19 & 5.8 & 149 & 45.4 & 151 & 46 \\
\hline Mother & 3 & 0.9 & 2 & 0.6 & 2 & 0.6 & 166 & 50.6 & 155 & 47.3 \\
\hline Spouse & 3 & 0.9 & 28 & 8.5 & 6 & 1.8 & 87 & 26.5 & 204 & 62.2 \\
\hline Brother & 16 & 4.8 & 22 & 6.7 & 91 & 27.8 & 139 & 42.4 & 60 & 18.3 \\
\hline Sister & 22 & 6.7 & 16 & 4.8 & 39 & 11.9 & 184 & 56.1 & 67 & 20.5 \\
\hline Other & 34 & 10.4 & 12 & 3.7 & 2 & 0.6 & 5 & 1.5 & 275 & 83.8 \\
\hline
\end{tabular}

Table 4. Relatives' addiction history (years)

\begin{tabular}{cccc}
\hline Relationship & Mean \pm SD & Min & Max \\
\hline Father & $12.10 \pm 27.93$ & 1 & 45 \\
\hline Mother & $15.36 \pm 19.5$ & 1 & 40 \\
\hline Spouse* & $0.71 \pm 0.5$ & 0 & 1 \\
Brother & $5.78 \pm 13.25$ & 5 & 20 \\
\hline Sister & $5.66 \pm 4$ & 0.5 & 8 \\
\hline
\end{tabular}

URA

* Of spouse, only 2 persons responded, one chose 0 and the other chose 1 . A min. of 0 and a max. of 1 . For these two figures, the Mean $\pm S D$ is $0.5 \pm 0.71$.

of the sample members were workers before addiction, but they became unemployed after addiction. So that the percentage of unemployed people was about $12 \%$ before addiction and about $24 \%$ after the addiction, that is, unemployment after addiction has increased about twice. About $35.9 \%$ of respondents were addicted for less than 8 years. Finally, $33.8 \%$ of the sample members became addicted between the ages of 16-22 years. Table 2 presents the results of a descriptive analysis of the age of the onset of synthetic drug use.

In addition to the above findings, $55.5 \%$ of the sample members used crystal at the onset of addiction. But now this percentage has risen to $69.5 \%$. Family members, friends, and peers have had the largest share in taking care of the person at the start, and $68.9 \%$ of respondents under the age of 6 have been taking synthetic drugs. About $36 \%$ of the people used the drug twice a day, which was the most frequent group. Also, $51.2 \%$ of addicts consumed the drug through inhalation.
Regarding the cost of procurement of drugs, the highest frequency $(26.2 \%)$ is in the range of 1 to 3 US dollars. The family of addicts provided the cost of drugs for about $65.9 \%$ of the addicts. Also, $59.1 \%$ of addicts consumed drugs outside of the home. Around $54.9 \%$ of people use industrial narcotics to get more stoned. About $51.8 \%$ of people continually used drugs. And $37.8 \%$ of the people considered the cause of relapse and re-use of the substance as a relief.

Table 3 presents that the majority of synthetic drugs addicts in Birjand City are among the working category.

Statistical data indicate that the Mean \pm SD ages of parents and respondents were $58.22 \pm 10.32$ years and $53.30 \pm 8.99$ years, respectively. The highest frequency of education in each of the relatives of sample members is under the diploma, and also the most frequent place of birth for family members was Birjand.

Table 4 presents the results of a descriptive analysis of the history of addicted relatives of respondents. For 
Table 5. Test results for hypotheses

\begin{tabular}{|c|c|c|}
\hline Hypothesis & $\mathbf{P}$ & The Spearman Correlations \\
\hline $\begin{array}{l}\text { There is a relationship between the age of the individual and the duration of addiction } \\
\text { to synthetic drugs }\end{array}$ & 0.384 & 0.000 \\
\hline $\begin{array}{c}\text { There is a relationship between the age of the person and the age of the onset of } \\
\text { addiction }\end{array}$ & 0.001 & 0.194 \\
\hline There is a relationship between education level and the age of the onset of addiction & 0.045 & 0.115 \\
\hline There is a difference regarding the type of occupation among addicts & 0.012 & 0.208 (Cramer's V) \\
\hline $\begin{array}{l}\text { There is a relationship between the age of synthetic drugs addiction and the frequency } \\
\text { of daily intake of drugs }\end{array}$ & 0.041 & 0.123 \\
\hline $\begin{array}{c}\text { Most of the drug addicts live in the ecological-biological community of the northern } \\
\text { part of Birjand City }\end{array}$ & 0.000 & 11.259 (Chi-squared) \\
\hline $\begin{array}{l}\text { There is a relationship between the presence of addicts in the family and the rate of } \\
\text { addiction to synthetic drugs }\end{array}$ & 0.035 & 0.627 (Cramer's V) \\
\hline Most synthetic drug addicts were born and lived in Birjand City & 0.000 & 1250.897 (Chi-squared) \\
\hline
\end{tabular}

example, the Mean \pm SD durations of addiction to parents and respondents were $27.93 \pm 12.10$ and $19.5 \pm 15.36$ years, respectively.

\section{Discussion}

The findings of the research, on the one hand, confirm the statistics and the status of the statistical population, the study's environment, exploratory interviews, conceptual definitions, and on the other hand, are consistent with the similarity, differential societies, and the results of previous research. As mentioned above, Birjand City is the capital of the Southern Khorasan Province. Because of its neighboring with the provinces of Kerman, Sistan, and Baluchestan, and having a common border of more than $460 \mathrm{~km}$ with Afghanistan, the largest producer of narcotics, Birjand is continuously exposed to the dangers of drug abuse. One of the results of the research was that most drug addicts are located in the ecologicalbiological branch of the northern site of Birjand City (Table 5).

As Mohseni has mentioned, our results also show that drug addiction is not just a personal behavior, but it affects other people and social behavior as well [2]. The results showed that the addicts were family members and peers. And even the family takes care of the cost of synthetic drugs in most cases. One of the results of the present study is that the causes of drug use tendency spread among friends, which requires more lookout of friends and better supervision of families.

Among the previous studies, the results of this study are consistent with some of the results of Raskh and Panahzadeh study [20]. Their results showed a significant relationship between self-concept variables, level of accountability education, access to drugs, family support, age, early sexual intercourse, self-esteem, hope for the future, and socializing with addicts and substance abuse. Also, there is a relationship between the social variables associated with it, the place of residence, and the type of substance abuse.

In this research, family support in the provision of drugs, concerning the person at the onset of addiction, age, education, and in relation with the addicts in the family, were very effective in addiction, although in some cases, there were no statistically significant results. The effect of the environment on the individual is not denied, and the effects of other variables in this field should be considered. Meanwhile, in this research, the researcher did not find any significant difference between the level of parenting education, parent's job, individual occupational status, ethnicity, addiction to a number of household members, and substance abuse.

One of the results of this study was that at least one of the members of the family had a synthetic drug addiction 
that could be matched by social factors affecting the use of narcotics in the Jorablo study [12]. Raeisi Sartashizi [11] found a significant relationship between social class variables, social control, and spending leisure time as the dependent variable (the rate of injecting drug use). In this research, addicts were the majority of working families. Also, the results of Raeisi Sartashizi [11] revealed a direct and significant relationship between the rate of drug use tendency and the variables of using modern media, the unproductive family, and socializing with inferior friends. The study also found that nearly half of the families of addicts live apart from each other or have divorced parents, as well as socializing with inferior friends, who accompany them at the onset of the relationship.

Ghadeghmat and Mahmoudi [19] studied the tendency of young people in Dorud City to synthetic drugs. Statistical analysis showed that the primary influential factors in addiction tendency included the presence of addicted people in family and relatives, socializing with addicted friends, divorce or death of parents, low-level education of the individual and parents, lack of enjoying healthy recreation, crowded family, easy access to drugs, unemployment, and poverty. In this research, some results, such as the relationship between unemployment and addiction, addiction, and education, have been effective factors. Findings of Mirzai Alaviyeh et al. study [16] also showed that in the dependent group, the cases of shaky life elements, low educational level of samples and their parents, low living standards, the presence of addicted father and brother and the prevalence of drug use in friends were significantly more than those in the non-addicted group. The most commonly used drug in the dependent group was crystal. In some cases, the study also had similar results.

The limitations of this research are as follows:

1. Since this research is limited to Birjand City, its generalization to other places should be made with caution; 2. The psychological conditions of the research's subjects may have been effective in answering some of the questions; 3. Data collection in most subjects (due to the high number of illiterate and low-literate people) confronted with some difficulties, so some addicts may not have responded to some questions for a variety of reasons; 4. Some addicts did not cooperate due to fatigue and impatience; 5. Collecting data from most addicts was difficult because of the community's attitude towards their addiction; 6 . It is time-consuming to access an interview with these people.

\section{Study Recommendations}

This research can be carried out in other cities of South Khorasan Province. Due to the younger age of addiction, a course should be introduced in the high-school curriculum to familiarize students with the complications and damages of narcotics, and in particular synthetic drugs. A textbook should be taught to prevent addiction in the high-school period.

In future studies, it is better to interview the statistical community to collect data qualitatively. Educational programs and curriculums can be developed and presented to promote self-esteem, to develop powers, and to train the skill of "saying no" to youth and adolescents against compliments to use narcotics, especially synthetic drugs due to its highly addictive property by families, schools and mass media.

Researchers can try to inform youth and promote their knowledge and insights on the harms, disadvantages, and adverse effects of using drugs, especially synthetic drugs, through schools, universities, religious communities, as well as mass media like TV.

\section{Conclusion}

As mentioned earlier, one of the most critical problems of addiction among communities is its social damages. The harms caused by it are far greater than other social problems because if addiction is considered as a criminal phenomenon and social harm, the problem would not be solved, rather addiction itself is the beginning of other social harms.

Also, statistics supported the increasing tendency for industrial narcotics. According to the reports of international organizations and institutions, attitudes and behavioral patterns of people, especially youth, have been affected by changes in the pattern of drug abuse in all parts of the world that is rapidly changing from traditional drugs to synthetic drugs.

Over the past 10 years, the rate of drug abuse has been increased from $3 \%$ to $25 \%$ [8]. The head of Iran Drug Control Headquarters in Birjand announced that the number of discoveries of industrial narcotics in 2016 was $90 \%$ higher than that in 2015 and, unfortunately, younger ages and between 20 to 30 years were most affected. The study also found that most young people started their addiction at the age of 16 . Also, according to the vice president of strategic and social protection and crime prevention judiciary, the third volume of cases in 
the country belonged to drug-related offenses [17]. Additionally, observations of the proficient narcotic experts indicated that $60 \%$ of this amount is related to synthetic drugs. All these statements are consistent with the study results as a tendency to use synthetic drugs was found more than $60 \%$

\section{Ethical Considerations}

\section{Compliance with ethical guidelines}

Ethical approval (Code: 34951/د) on 6 january 2020.

Funding

This article is extracted from MA thesis of Mohsen Khosravi at Islamic Azad University, Gonabad Branch, Gonabad.

\section{Authors' contributions}

Study design: Mohsen Khosravi; Data collection and analysis: Bibiagdas Asghari; Manuscript preparation: Maryam Eskafi.

\section{Conflict of interest}

The authors declared no conflict of interests.

\section{Acknowledgments}

The authors appreciate the Iran drug control headquarters as a sponsor of this research of all participants in this research.

\section{References}

[1] Bahrami Ehsan H. [Addiction and process of prevention (Persian)]. 4t $\mathrm{t}^{\mathrm{h}}$ ed. Tehran: SAMT; 2012. http://opac.nlai.ir/ opac-prod/bibliographic/2780953

[2] Mohseni M. [Sociology of social deviance (Persian)]. Tehran: Tahoori; 2007. http://opac.nlai.ir/opac-prod/bibliographic/988836

[3] Miri Ashtiani E, Tajik MR. [Sociology of addiction in in today's Iran (Persian)]. Tehran: Mohajer; 2006. http:/ / opac.nlai. ir/opac-prod/bibliographic/766667

[4] Winks C, Norman RL. Epidemiology. In: Lowinson $\mathrm{JH}_{4}$ Ruiz P, Millman RB, Langord JG, editors. Substance Abuse: A Comprehensive Textbook. $4^{\text {th }}$ ed. Philadelphia: Lippincott Williams \& Wilkins; 2005. pp. 15-32. https://books.google. com/books?id=HtGb2wNsgn4C\&vq
[5] Spain National Plan on Drugs. National drugs strategy 20002008. Spain: Spain National Plan on Drugs; 2008.

[6] Lowinson JH, Ruiz P, Millman RB, Langord JG, editors. Substance abuse: A comprehensive textbook. $4^{\text {th }}$ ed. Philadelphia: Lippincott Williams \& Wilkins; 2005. https://books.google. com/books?id=HtGb2wNsgn4C\&vq

[7] Green LW, Ottoson JM. Community health. $7^{\text {th }}$ ed. Maryland Heights: Mosby; 1995.

[8] Allahverdipour H, Hidarnia AR, Kazemnejad A, Shafii F, Azad Fallah P, Mirzaee E, et al. [Assessment of substance abuse behaviors in adolescents': Integration of self-control into extended parallel process model (Persian)]. J Shahid Sadoughi Univ Med Sci. 2005; 13(1):21-31. http://jssu.ssu.ac.ir/ article-1-1348-en.html

[9] Eskandari M. [Investigating the factors affecting the tendency of Youth to stimulant drug use (Persian)]. J Soc Secur Stud. 2010; 21:11-32.

[10] Aghabakhshi H, Seddighi B, Eskandari M. [A survey on the effective factors of the youths' tendency towards industrial drugs abuse (Persian)]. Soc Res. 2009; 2(4):71-87. https:/ / www.sid.ir/fa/Journal/ViewPaper.aspx?id=112201

[11] Javanmard K, Goodarzi R. [A study of social factors affecting adolescents' and youth's tendency to narcotics (Persian)] Paper presented at: $2^{\text {nd }}$ International Conference on Modern Researches in the Field of Educational Sciences and Psychology and Social Studies of Iran, Soroush Hekmat Mortazavi Center for Islamic Studies and Research. 26 February 2017 Qom, Iran. https://www.civilica.com/Paper-ESCONF02ESCONF02 218.htm

[12] Khademian T, Ghenaatian Z. [A study of social factors affecting drug addiction in drug rehabilitation centers and reducing the harm to women in Tehran (Persian)]. J Soc Sci. 2009; 2(4):59-85. http://ensani.ir/fa/article/229732/

[13] Pashmdoost M, Ghaffari O. [The effectiveness of metacognitive group therapy in substance withdrawal and its stability (Persian)]. Res Addict. 2015; 9(34):99-110. http:/ / etiadpajohi. ir/article-1-677-fa.html

[14] Basharpoor S. [Structural relation pattern between deviant personality traits, risk perception and treatment motivation in people with substance dependency: The mediating role of risk perception (Persian)]. Res Addict. 2016; 9(35):99-117. http://etiadpajohi.ir/article-1-1028-fa.html

[15] Shamshiri M. [The effectiveness of problem-solving skills training on improving coping styles, readiness for change and eagerness for the treatment and prevention of relapse in addicts referring to addiction treatment centers in Khash (Persian)] [MSc. thesis]. Zahedan: University of Sistan and Baluchestan; 2013. https://ganj-old.irandoc.ac.ir/articles/607557

[16] Mirzaei Alavijeh M, Nasirzadeh M, Eslami AA, Sharifirad GR, Hasanzadeh A. [Influence of family function about youth dependence to synthetic drugs (Persian)]. Iran J Health Educ Health Promot. 2013; 1(2):19-30. http://journal.ihepsa.ir/ article-1-85-en.html

[17] Islamic Republic News Agency. [IRNA's most importan news headlines from Monday evening to Tuesday morning (Persian)] [Internet]. 2017 [Updated 2017 May 9]. Available from: https://www.irna.ir/news/82522081/ 
[18] Liettieri DJ, Sayers M, Pearson HW, editors. Theories on drug abuse [MA. Zakriaei, Sh. Vakili, M. Rezaei, Persian trans.]. Tehran: Jame'e va Farhang; 2005. http://opac.nlai.ir/ opac-prod/bibliographic/755531

[19] Ghaeed Rahmat E, Mahmoodi M. [Investigating the tendencies of young people in Dorood city to industrial drugs (Persian)]. Paper presented at: National Conference on Psychology of Educational and Social Sciences. 27 August 2015; Mazandaran, Iran. https://www.civilica.com/PaperSEPP01-SEPP01_133.html

[20] Rasekh K, Allah Panahzadeh T. [Social factors affecting on drugs abuse: (Slum dwellers in Shiraz-Iran) (Persian)]. Sociol Stud Youth (Jame Shenasi Motaleate Javanan). 2012; 3(7):25-42. https://www.sid.ir/fa/journal/ViewPaper.aspx?ID=202128 
This Page Intentionally Left Blank 